Acta Cryst. (2002). A58 (Supplement), C63

\section{OVERVIEW OF IUCr JOURNALS}

J. Helliwell

CCLRC Daresbury Laboratory Synchrotron Radiation Department Keckwick Lane Daresbury Warrington CHESHIRE WA4 4AD UK

In the triennium since the Glasgow Congress major accomplishments have included the '50-Year Digitization Project', the launch of Acta Crystallographica Section E, regular highlighting of articles in the IUCr Newsletter, the drafting and dissemination of promotional leaflets as well as the publication in the period 1999-2001 of 25639 pages and 6121 articles across the 7 IUCr Journals, compared with 21947 pages and 5196 articles across 6 journals in the period 1996-1998. The coordination of the Journals portfolio has been considerably expedited via implementation of a Journals Working Group (JWG) which meets regularly through the year. In the coming triennium we can expect further enhancements of publication speed as yet faster e-communication occurs. All of this rests on the superb work at IUCr Chester, UK, by the technical editing, R\&D, promotional as well as executive team. This formula is working well with buoyant regular issues across nearly all titles.

For the Journal of Synchrotron Radiation, however, the number of regular articles has been lower than hoped, in part because the SR community has retained enthusiasm for Conference Proceedings. The Open Commission meeting will allow discussion of this and any other topics that the community wishes to raise. A special session of the Journals Commission and the Biological Macromolecules Commission (Chair: M. Guss) will address structural genomics publishing.

\section{Keywords: JOURNALS PUBLISHING JCOMM}

Acta Cryst. (2002). A58 (Supplement), C63

\section{JOURNAL OF SYNCHROTRON RADIATION: CURRENT STATUS} AND ISSUES

D. M. Mills ${ }^{1}$ S. S. Hasnain ${ }^{2}$ H. Kamitsubo ${ }^{3}$

${ }^{1}$ Advanced Photon Source, Argonne National Laboratory ${ }^{2}$ Synchrotron Radiation Department, CCLRC Daresbury Laboratory ${ }^{3}$ SPring-8, JAERI-

The last triennium has seen a regular flow of issues of Journal of Synchrotron Radiation (JSR) every two months with articles covering topics such as X-ray diffraction, spectroscopy, imaging, and synchrotron radiation instrumentation developments. Major conference proceedings were published by JSR in 1999 (XAFS X) and in 2001 (XAFS XI), each having very large numbers of pages in a single issue, 686 and 968 pages, respectively. Thus for the calendar years 1999,2000 , and 2001 the overall number of published pages was 2883 . The articles published by JSR were of high quality as evidenced by the journal impact factor.

The synchrotron radiation (SR) community will be invited to debate the value of publishing conference proceedings for future issues of JSR. The International Committee of SR Facility Directors will also be consulted regarding their policy of having a triennial SR and XAFS conference proceedings. Although during the last triennium, the average of number of pages per issue was 160 , this number is highly skewed by the large conference proceedings.

The concern that the regular issues have rather too few pages will also be addressed. Noting that the SR field is very closely connected to the nascent field of x-ray free-electron lasers, discussion will be held on whether, and if so how, to encourage submission of articles from this cognate field.

DMM and Argonne National Laboratory are supported by the U.S. Department of Energy, Office of Science, Basic Energy Sciences, under contract \#W-31109-ENG-38.

\section{Keywords:JOURNAL OF SYNCHROTRON (JSR), SYNCHROTRON} RADIATION, IUCR
Acta Cryst. (2002). A58 (Supplement), C63

G. Kostorz

ETH Zurich, Angewandte Physik, CH 8093 Zurich, Switzerland

The Journal of Applied Crystallography, now in its 34th year, continues to be a broad international forum for the comprehensive coverage of all topics related to the application of crystallographic methods in all branches of the natural sciences, with some offshoots into technology. An overview of subject areas of some significance in recent years will be given, and some of the areas strongly represented as well as those with good potential for growth will be assessed. An analysis of the geographical origin of manuscripts will also give some indications of trends and further possibilities. Ideas for the future development of the journal will be discussed. Contributions to this discussion will be gratefully received before and during the session.

\section{Keywords: JOURNAL OF APPLIED CRYSTALLOGRAPHY CRYSTALLOGRAPHY JOURNALS ONLINE APPLIED CRYSTALLOGRAPHY}

\author{
P. R. Strickland M. Hoyland \\ International Union of Crystallography, 5 Abbey Square, Chester CH1 2HU, \\ England
}

Crystallography Journals Online now provides over 50 years of back issues of IUCr journals at the click of a mouse. The initial steps in this process were taken in 1986 when the first journal indexes were typeset in-house; a project to create a printed 20-year index for Journal of Applied Crystallography followed in 1989. With the advent of the IUCr web server in 1995, plans to create an electronic 50-year index were made; work on this was completed in 1998. In 1999, at the Glasgow Congress, the decision to digitize the complete back content of the journals was made. Journal originals were prepared and sent for scanning by the Higher Education Digitization Service at the University of Hertfordshire, UK, and the scanned images were assembled into PDFs by the IUCr in Chester. Details of the project will be described, together with work still to be carried out and some spin-off projects. Ideas for extending the digital crystallographic library in the next triennium will be presented.

\section{Keywords: CRYSTALLOGRAPHY JOURNALS ONLINE DIGITIZATION CRYSTALLOGRAPHIC LIBRARY}

